\title{
Monitoring AND QUANTIFYING PARTICles EMisSiONS AROUND INDUSTRIAL SITES WITH SCANNING DOPPLER LIDAR
}

\author{
L. Thobois ${ }^{1 *}$, P. Royer ${ }^{1}$, R. Parmentier ${ }^{1}$, M. Brooks ${ }^{2}$, A. Knoepfle ${ }^{2}$, J Alexander ${ }^{2}$, P.Stidwell ${ }^{2}$, R. \\ Kumar $^{2}$ \\ ${ }^{1}$ Leosphere: Lidar Environmental Observations, Orsay, France, *lthobois@leosphere.com \\ ${ }^{2}$ ECOTECH, Australia
}

\begin{abstract}
Scanning Coherent Doppler Lidars have been used over the last decade for measuring wind for applications in wind energy [1], meteorology [2] and aviation [3]. They allow for accurate measurements of wind speeds up to a distance of $10 \mathrm{~km}$ based on the Doppler shift effect of aerosols. The signal reflectivity (CNR or Carrierto-Noise Ratio) profiles can also be retrieved from the strength of the Lidar signal. In this study, we will present the developments of algorithm for retrieving aerosol optical properties like the relative attenuated backscatter coefficient and the mass concentration of particles. The use of these algorithms during one operational trial in Point Samson, Western Australia to monitor fugitive emissions over a mine will be presented. This project has been initiated by the Australian Department of Environment Regulations to better determine the impact of the Port on the neighboring town. During the trial in Summer, the strong impact of turbulence refractive index on Lidar performances has been observed. Multiple methodologies have been applied to reduce this impact with more or less success. At the end, a dedicated setup and configuration have been established that allow to properly observe the plumes of the mine with the scanning Lidar. The Lidar data has also been coupled to beta attenuation in-situ sensors for retrieving mass concentration maps. A few case of dispersion of plumes will be presented showing the necessity to combine both the wind and aerosol data.
\end{abstract}

\section{INTRODUCTION}

Mining, quarrying and cement manufacturing plants, as with other heavy industrial activities involve a series of operations which can produce significant quantities of fugitive particles like dust or soot, with potentially adverse effects on the local and neighboring environments. Effective control of their occurrence is necessary in order to comply with environmental regulations involving the maximum level of particle emissions, and also in order to optimize the operational processes of these industries. At some locations, industrial emissions can also be limited by the background level of particles as in desert areas, where dust concentration can be close to the maximum level of particles permitted. In addition to conventional in-situ particles counters located at specific points, the monitoring in $2 \mathrm{D}$ of particles around industrial plants allows for better characterization and thus management of particles emissions.

\section{EXPERIMENTAL SETUP}

A WINDCUBE200S Scanning Doppler Lidar [4] was installed for a 3-month campaign at an Iron Ore Port facility on the West coast of Australia (see on figure 1). The main objective of this campaign is to quantify the emissions from the port Iron Ore stockpiles and ship loading operations (see orange area on figure 1) and to determine its impact on the nearby town (see blue area on figure 1). 


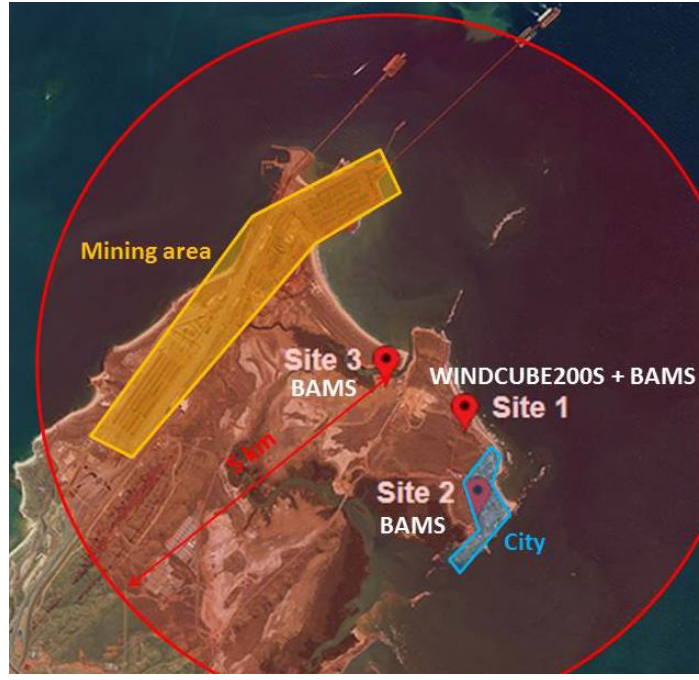

Figure 1 Experimental setup

The scanning Lidar has been lifted $9.5 \mathrm{~m}$ above the ground level in order to reduce the impact of the refractive index turbulence on the Lidar instrumental function.

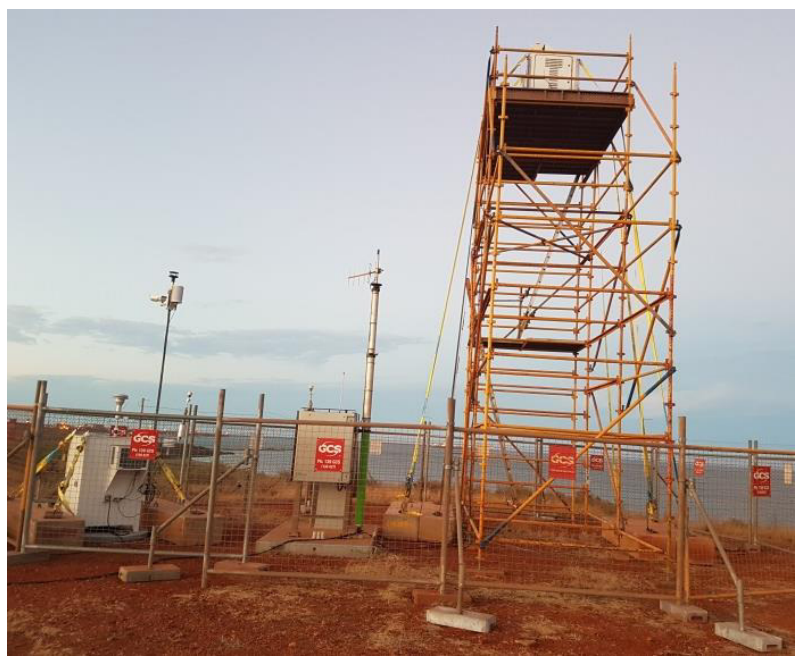

Figure 2 WINDCUBE200S and BAMS installation on site 1

Lidar measurements are performed with a range resolution of $50 \mathrm{~m}$, an accumulation time of $1 \mathrm{sec}$ and a scan rate of $1 \% \mathrm{sec}$. The scenarios of measurements are detailed in Table 1 and consist in a 10min sequence with one full PPI (Plan Position Indicator), 2 RHI cross-sections (Range Height Indicator) and $2 \mathrm{~min}$ of vertical LOS (Line-Of-Sight).

\begin{tabular}{|c|c|c|c|c|c|}
\hline & \multicolumn{2}{|c|}{ Azimuth } & \multicolumn{2}{|c|}{ Elevation } & \multirow[t]{2}{*}{ Duration } \\
\hline & Start & End & Start & End & \\
\hline PPI & 0 & 360 & \multicolumn{2}{|c|}{$0.25^{\circ}$} & $360 \mathrm{sec}$ \\
\hline RHI 1 & \multicolumn{2}{|c|}{$167^{\circ}$} & -2 & 45 & $47 \mathrm{sec}$ \\
\hline RHI 2 & \multicolumn{2}{|c|}{$308^{\circ}$} & -2 & 45 & $47 \mathrm{sec}$ \\
\hline $\begin{array}{l}\text { Vertical } \\
\text { LOS }\end{array}$ & \multicolumn{2}{|c|}{$0^{\circ}$} & \multicolumn{2}{|c|}{$90^{\circ}$} & $120 \mathrm{sec}$ \\
\hline
\end{tabular}

The relative attenuated backscatter coefficient $\left(\beta_{\text {rel.att. }}\right)$ is computed by removing the instrumental function $(F)$ to the Carrier-to-Noise Ratio $(C N R)$ :

$$
\beta_{\text {rel.att. }}(r)=\frac{C N R(r)}{F(r)}
$$

The instrumental function is determined by fitting a lorentzian shape function on horizontal measurements in homogeneous atmospheric conditions.

The optical-to-mass conversion factor $A$ is determined by correlation between in-situ BAMS (Backscatter Moessbauer Spectrometer) 1-hour averaged mass concentration $\left(C_{B A M}\right)$ and the 1hour averaged relative attenuated backscatter coefficient $\left(\beta_{\text {rel.att. }}\right)$ from lidar measurements at the BAMS location:

$$
A(t)=\frac{\overline{\beta_{\text {rel.att. }}(t)}}{C_{B A M(t)}}
$$

This conversion factor is then applied to Lidar data to give a real-time estimate of the mass concentration. This method has been used since several comparisons between Lidar and BAMS data have shown that these two quantities are highly correlated in the same kind of environment.

The correlation between measured BAMS and lidar-derived concentrations is given on figure 3 . 


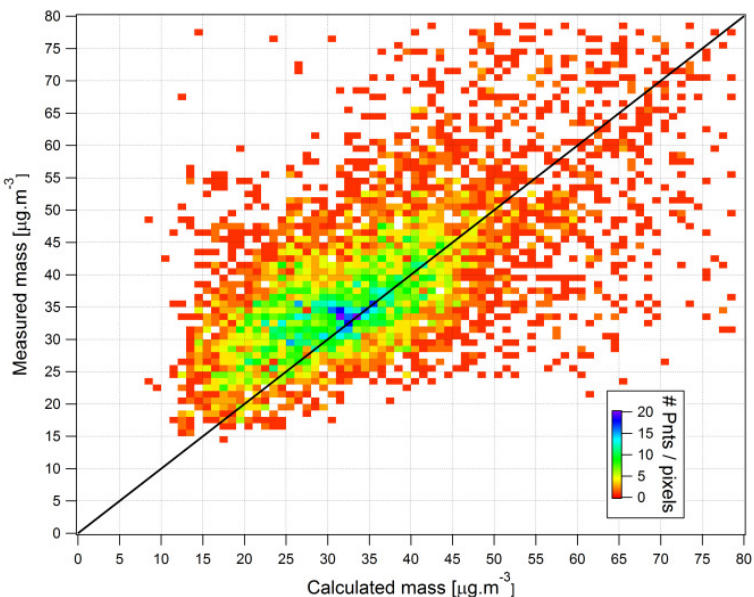

Figure 3 Correlation between measured BAMS mass concentrations and calculated WINDCUBE mass concentrations

\section{RESULTS}

BAMS measurements and real-time estimated aerosol concentrations from the Lidar are available online http://airodis.ecotech.com.au/derLidar/index.html.

Two examples of mass concentrations observations are given on figure 4. Concentrations are divided into 6 categories:

- Level 0 (in transparent) for concentrations $<40 \mu \mathrm{g} / \mathrm{m}^{3}$

- Level 1 (in yellow) for concentrations > $40 \mu \mathrm{g} / \mathrm{m}^{3}$

- Level 2 (in orange) for concentrations > $60 \mu \mathrm{g} / \mathrm{m}^{3}$

- Level 3 (in red) for concentrations > 100 $\mu \mathrm{g} / \mathrm{m}^{3}$

- Level 4 (in purple) for concentrations > $350 \mu \mathrm{g} / \mathrm{m}^{3}$

- Solid (in grey) for concentrations $>500$ $\mu \mathrm{g} / \mathrm{m}^{3}$
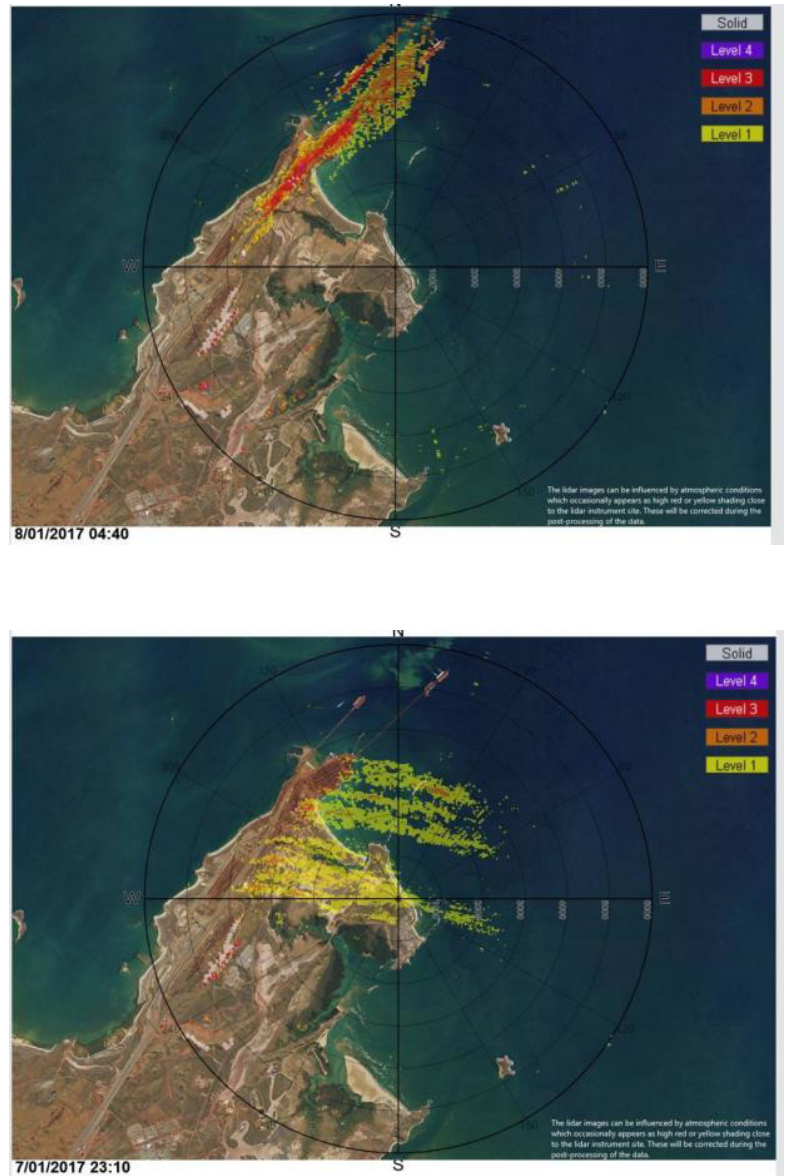

Figure 4 Mass concentration observations over the mining site

The plumes dust plumes are clearly visible on the two examples with an extension of more than 4 $\mathrm{km}$. In the first case the concentration are higher and level 3 is reached in the center of the plume. The Scanning Doppler Lidar also enables to localize the emission source.

\section{CONCLUSIONS}

We present here an example of use of scanning Doppler Lidar for the monitoring and the quantification of particle emissions over an industrial mining site.

Doppler Lidar relative attenuated backscatter measurements were correlated to BAMS in-situ concentrations in order to derive the optical-tomass conversion factor. This conversion is then applied to the Lidar measurement in order to give a real-time estimate of the mass concentration. This real-time information is particularly 
important for mining industry to regulate and reduce the dust emissions with water sprays.

As perspectives, the wind and mass concentration data will be combined and analyzed to better determine the dispersion of the aerosol with wind and turbulence. Besides, these studies show that Coherent Doppler Lidars can provide aerosol optical properties with a good accuracy and sensitivity like direct detection Lidars if the phase of the coherent signal is not affected by the refractive turbulence index.

[1] Krishnamurthy et al., 2012: Coherent Doppler lidar for wind farm characterization, Wind Energy, DOI: 10.1002/we.539, 16, 189-206.

[2] Frehlich et al., 1998: Coherent Doppler lidar measurements of wind field statistics, BoundaryLayer Meteorology, 86, 233-256.

[3] Shun and Chan, 2008: Applications of an Infrared Doppler LIDAR in Detection of Windshear, Journal of Atmospheric and Oceanic Technology, DOI:

http://dx.doi.org/10.1175/2007JTECHA1057.1， 25, $637-655$

[4] Thobois et al., Sept. 2016: New York State Mesonet, Meteorological Technology International, 62-65. 